\title{
ERT Challenges in the Post-2015 Era ${ }^{1}$
}

\author{
Manzoor Ahmed* \\ Institute of Educational Development, BRAC University, Dhaka, Bangladesh
}

\begin{abstract}
This paper provides a background to the on-going discourse on post-2015 global development agenda. It mentions key points from the UN Secretary General's report on MDG progress and the process of formulating the future development agenda. The recommendations of the High Level Panel on post-2015 agenda and the work of the Sustainable Development Solutions Network (SDSN) are examined from the perspective of Education for Rural Transformation (ERT). It is concluded that the premise and rationale of ERT has received scant attention in the future development agenda discourse. The arguments regarding the pertinence of ERT in combating poverty and promoting sustainable development are noted, drawing on the recent UNESCO- INRULED study on this topic.
\end{abstract}

Keywords: Education for Rural Transformation, Post-2015 Development Agenda, Combating Poverty, Skills and Jobs for Rural Transformation, Skills and Jobs for Green Future

\section{Background}

Even before we get there, 2015, the target year for achieving the Millennium Development Goals (MDG) and the Education for All (EFA) goals set in 2000, has become a chronological watershed. This is so in respect of assessing the state of national and global development in the run-up to 2015, the discourse on rethinking and re-conceptualizing development and setting the agenda for the future at least up to 2030. A meaningful discussion about "rural transformation" and the place of education and learning in it cannot happen outside or without reference to the framework of the on-going MDG review and the current dialogue and debates about the post-2015 development agenda.

The MDGs and EFA goals, set at the same time with the same time-frame, have influenced national development priorities and strategies in an unprecedented way. Unprecedented, because such an agenda of a global scope had never been taken up collectively by the international community. Its significance is unparalleled regardless of 
ERT Challenges in the Post-2015 Era 73

what the eventual judgment is on the degree of achievement of the goals. It can be seen as a mixed score card, but the achievements so far have been rather remarkable in historical terms.

\section{ERT in the MDG Progress Report}

The Secretary General of the United Nations reported to the General Assembly on 26th July, 2013 about "progress towards the Millennium Development Goals and advancing the United Nations development agenda beyond 2015" (United Nations, 2013). The report points out successes and challenges. The succinct summation is cited below at some length, because it illustrates how some aspects of the critical concerns which we would like to be addressed are missed out:

At the global level, poverty and hunger have been reduced significantly. In developing regions, the proportion of people living on less than $\$ 1.25$ a day fell by more than half, from 47 per cent in 1990 to 22 per cent in 2010, with the majority living in rural areas....[emphasis added]. 1.2 billion people are still living in extreme poverty.... in subSaharan Africa; the number of people living in poverty is rising...

The target of halving the percentage of people suffering from hunger by 2015 is within reach. .. However, one in eight people remain chronically undernourished, and one in four children suffers from stunted growth because of malnutrition...

We risk failing to keep our promise to enable all children to go to school... progress has slowed significantly over the past five years. Without renewed efforts, the target of universal primary education by 2015 seems beyond reach...

Women and girls are major drivers of development.... In many developing countries, girls are denied their right to primary education. Women have been gaining employment in non-agricultural sectors, but often in less secure jobs with fewer social benefits than those held by men...

Some of the targets for ensuring environmental sustainability have been achieved: the target for improved water sources was met ahead of schedule, and over the past decade over 200 million slum dwellers - double the target - benefited from improved water and sanitation facilities, durable housing or sufficient living space...

[However]... in all countries, the achievement of Goal 7, on ensuring environmental sustainability, remains at significant risk because of the profound and urgent challenges posed by climate change. Carbon dioxide emissions are more than 46 per cent higher than in 1990. The atmospheric concentration of carbon dioxide has exceeded 400 parts per million, a level not seen in millions of years and threatening the existence of the planet...

As shown in the forthcoming MDG Gap Task Force Report 2013, progress towards a global partnership for development has fallen short of expectations.

Despite welcome gains in connectivity, a substantial digital divide remains between developed and developing regions. (United Nations 2013, pp. 4-6) 
74 M. Ahmed

How are the rural people and rural areas figured in the summation of MDG progress? It is noted that of almost a quarter ( 22 percent) of the world population still living in serious poverty, the majority are in rural areas. The implication, though not specifically underscored, is that in all the areas of the shortfall in achievement and continuing disparities among population groups, the rural people are adversely and disproportionately affected.

In presenting a vision and transformative actions to advance a post-2015 development agenda, the Secretary General mentions that 70 per cent of the world's population will live in cities by 2050 . And therefore, employment, food, income, housing, transportation, clean water and sanitation, social services and cultural amenities will have to be provided for the city dwellers.

The flip side of this situation of course is that about a third of the population will still live in rural areas and much larger proportions will continue to be there from now till 2050, including the majority of the world's poor. Moreover, in many countries, the definition of "urban" includes land and people bearing the characteristics of "rural." In China, for example, half of the population counted as urban are estimated to live, in terms of the habitation pattern, economic activities and access to civic amenities, a rural life, though they are within administrative boundaries of the city.

The Secretary General's report does mention that "rural prosperity, land management and secure ecosystem services should form an integral part of sustainable urbanization and economic transformation" (p. 15). Note, however, that the stress is on sustainable urbanization rather than sustainable integrated urban-rural development.

\section{HLP Position and ERT}

The report of the Secretary General draws heavily on the work of the High Level Panel (HLP) of "eminent persons" appointed a year earlier to undertake dialogue widely about the post-2015 global development agenda and present the findings and recommendations to the Secretary General. The HLP was co-chaired by Susilo Bambang Yudhoyono, President of Indonesia; Ellen Johnson-Sirleaf, President of Liberia; and David Cameron, Prime Minister of the United Kingdom. The Panel submitted its report entitled "A New Global Partnership: Eradicating Poverty and Transforming Economies through Sustainable Development" on 30 May, 2013 (HLP, 2013). The HLP in turn was influenced by what has come to be known as the Rio+20 process emerging from the Rio de Janeiro conference in June 2012 held on the 20th anniversary of the Earth Summit in 1992.

Because of the importance given to the HLP report in the UN-led discourse, it is appropriate to take note of its position on questions which are pertinent to ERT. It points out: 
... to fulfill our vision of promoting sustainable development, we must go beyond the MDGs. They did not focus enough on reaching the very poorest and most excluded people.... Most seriously, the MDGs fell short by not integrating the economic, social, and environmental aspects of sustainable development as envisaged in the Millennium Declaration, and by not addressing the need to promote sustainable patterns of consumption and production. The result was that the environment and development were never properly brought together. People were working hard - but often separately - on interlinked problems...

There are a billion more people today, with the world population at seven billion, and another billion expected by 2030. More than half of us now live in cities.... (emphasis added)...

Above all, there is one trend - climate change - which will determine whether or not we can deliver on our ambitions. Scientific evidence on the direct threat from climate change has mounted. The stresses of unsustainable production and consumption patterns have become clear, in areas like deforestation, water scarcity, food waste, and high carbon emissions. ...

Losses from natural disasters-including drought, floods, and storms - have increased at an alarming rate. People living in poverty will suffer first and worst from climate change. The cost of taking action now will be much less than the cost of dealing with the consequences later. (pp. 7-8)

The HLP concluded that the post-2015 universal agenda should be driven by "five big transformative shifts":

1. Move from reducing to ending extreme poverty, in all its forms (p. 8).

2. Halt the alarming pace of climate change and environmental degradation, which pose unprecedented threats to humanity (p. 8).

3. A quantum leap forward must be taken in economic opportunities and a profound economic transformation to end extreme poverty and improve livelihoods, using cities and rapid urbanization as the engines for business and innovation (emphasis added) (pp. 8-9).

4. Build peace and effective, open and accountable institutions for all (p. 9).

5. Forge a new global partnership in a spirit of solidarity, cooperation, and mutual accountability that must underpin the post-2015 agenda (p. 9).

The HLP declares that developing a single, sustainable development agenda is critical. "Pursuing a single, sustainable development agenda is the right thing, the smart thing and the necessary thing to do," the report says (p.18). It does assert that the agenda must connect people in rural and urban areas to the modern economy through quality infrastructure - electricity, irrigation, roads, ports, and telecommunications (p.19). But then it reverts to a single-minded focus on urbanization as noted below. 
The five transformative shifts are expected to underpin the goals or the agenda for development - presented by HLP as illustrated under 12 headings:

(i) end poverty; (ii) empower girls and women and achieve gender equality; (iii) provide quality education and lifelong learning; (iv) ensure healthy lives; (v) ensure food security and good nutrition; (vi) achieve universal access to water and sanitation; (vii) secure sustainable energy; (viii) create jobs, sustainable livelihoods and equitable growth; (ix) manage natural resource assets sustainably; (x) ensure good governance and effective institutions; (xi) ensure stable and peaceful societies; and (xii) create a global enabling environment and catalyze long-term finance. (p. 28)

The goals are followed by listing a set of cross-cutting issues, as these cannot be addressed by a single goal. This list includes peace, inequality, climate change, cities, concerns of young people, girls and women, and sustainable consumption and production patterns (p. 28).

Of particular relevance from the ERT point of view is the cross-cutting theme of cities. The HLP asserts, "The post-2015 agenda must be relevant for urban dwellers. Cities are where the battle for sustainable development will be won or lost" (p. 29).

The Panel does say it "also believes that it is critical to pay attention to rural areas, where three billion near-poor will still be living in 2030" (p.29). It goes on to say:

The most pressing issue is not urban versus rural, but how to foster a local, geographic approach to the post-2015 agenda. The Panel believes this can be done by disaggregating data by place, and giving local authorities a bigger role in setting priorities, executing plans, monitoring results and engaging with local firms and communities. (p. 29)

The assertion that "the most pressing issue is not urban versus rural, but how to foster a local, geographic approach to the post-2015 agenda" is welcome and critical from the point of view of ERT. However, this is not followed through in the argumentation and the positions taken in the report. The ambivalence, if not a strong bias, in the panel, not just on the urbanization issues, but in much of the discourse on sustainable development, is palpable when the question of rural people, rural economy, and rural development arises. One cannot but form the impression that the preferred solutions are those framed in terms of the cities' needs, rather than from the point of view of an integrated and mutually supportive regional perspective encompassing urban, peri-urban and rural, recognizing that the boundaries are transient.

The global goals, targets and indicators are justifiable on the ground of the need to proclaim a common purpose, to express human solidarity and to have common rallying points. At the same time the circumstances and needs are diverse among and within countries and population groups, which require the goals, targets and indicators to be 
adapted and adjusted. All are not necessarily pertinent everywhere; specific deviations are called for in diverse situations.

The HLP recognizes that the discussion on post-2015 agenda has highlighted that the MDG 2015, contradicting to a degree the spirit and core principle of the UN Millennium Declaration of 2000, took an economistic view of development. It underscored poverty reduction, emphasizing income poverty, as the first, and presumably, the most important MDG, to the achievement of which other goals would contribute. To what extent and how are the pitfalls of this restrictive view being addressed in the new agenda? Is it enough to add the mention of planetary limits to development, strongly pushed by the RIO+20 community, to the poverty goal? (Ahmed, 2013a, 2013b).

\section{SDSN Agriculture Report and ERT}

Emerging from the RIO+20 conference is the very active coalition called the Sustainable Development Solutions Network. It has identified some 13 themes on which thematic groups have been looking at and elaborating inputs to the post-2015 global development agenda-setting process. One of the themes of interest to those concerned about ERT, is sustainable agriculture and food systems. The report of the thematic group on sustainable agricultures and food systems has come out in September 2013 after the HLP report. It poses what it calls "tough questions" and attempts to answer these. Several of the questions would be familiar to those interested in ERT (See SDSN, 2013a). These include: How to make agriculture profitable and sustainable?

How to change consumer behavior in food?

How China can produce enough food for its people instead of depending on major imports?

Can India redirect investments to rural development and in fighting rural poverty?

How can Africa and Latin America use their land and water resources better?

Should small farms be consolidated to increase productivity leading to rural development and job creation?

How can research and technology harness biotechnology, genomics, IT revolution, physics and chemistry and material sciences to take agriculture to a new level of productivity and environmental efficiency?

Can urban farming contribute to feeding urban people?

How should current global, regional, and national policies on subsidies and trade be changed to enable equitable and sustainable agricultural development?

How can external assistance support sustainable agriculture?

How can the business climate be improved to have more investment in small business development? 
What new mechanisms and incentives induce public, civil society and private sectors to work together?

How is intellectual property honored but also made accessible to poorer countries? (SDSN 2013a)

These are pertinent questions. However, looking at these, one can justifiably argue that the report is largely inward-looking, in defining problems and finding solutions within the agriculture sector and the rural areas. The interface and interconnections between agriculture-rural to national-urban-global are ignored or they receive passing mention.

The SDSN report argues that aspirations of maximum consumption should be replaced by patterns of optimized consumption. The available technical solutions are well advanced, but we also need to overcome systemic political, economic and social barriers to change, which are substantial. Strong multi-sectoral cooperation will be needed to address the development challenges facing humanity and the planet (p. 81).

These exhortations should not be only about the rural areas and the agriculture sector; the implications for these have to be spelled out for and applied to the whole national economy and all the people - urban and rural, within countries and globally.

\section{SDSN Position on Cities}

An SDSN thematic group on cities also issued a report in September 2013 and proposed a stand-alone global goal for urbanization. A dedicated and stand-alone urban SDG is expected to accomplish the following (SDSN, 2013b):

* Educate and focus attention on urgent urban challenges and future opportunities;

* Mobilize and empower all urban actors around practical problem solving;

* Address the specific challenges of urban poverty and access to infrastructure;

* Promote integrated and innovative infrastructure design and service delivery;

* Promote land use planning and efficient spatial concentration, and;

* Ensure resilience to climate change and disaster risk reduction

Could the same arguments be put forward for a stand-alone sustainable rural development goal? Or, more appropriately, an integrated, mutually supportive urban- rural regional development goal? The "cities" document makes one reference to "rural" in these words: "The right to development for low-income and middle-income countries can only be realized through sustainable urbanization that addresses the needs of both rural and urban areas" (p. 2). Fair enough, but then the rest of the text is exclusively about urban areas without any mention of the need and possibility of mutual complementarity.

\section{SDSN Education Report}

SDSN Thematic Group 4 on "Early Childhood Development, Education and Transition to Work" argues that in the next 15 years the world will witness four shifts affecting education (SDSN, 2013c):

Journal of Education and Research, August 2014, Vol. 4, No. 2 
Looking forward towards the next fifteen years, there are four societal changes that can affect education: a growing young population in much of the developing world, in most parts of the world, people are becoming more mobile and urban, minimum skills for the world of work now need to go beyond numeracy and literacy, and finally, technology is changing our individual and collective lives. (p. 4)

The educational implications of these shifts are identified as; first, continuing (and in some cases widening) inequalities of access and participation; second, the target group for education is expanding; third, the content of learning and instruction will need to improve; and fourth, new ways have to be found to meet the teaching workforce, capacity building and governance challenges in delivering education (pp. 4-5).

The SDSN-proposed single education goal for post-2015 agenda is:

Goal 3: Ensure effective learning for all children and youth for life and livelihood.

Three sub-goals or targets are proposed -

Target 3a: All children under the age of 5 reach their developmental potential through access to quality early childhood development programs and policies.

Target $3 \mathrm{~b}$.All girls and boys receive quality primary and secondary education that focuses on learning outcomes and on reducing the dropout rate to zero.

Target $3 \mathrm{c}$. Youth unemployment rate (15-24 years) is below 10 percent.

The associated indicators propose monitoring access and effective participation for all as well as efficacy of governance and resource utilization, but the persistent disadvantages of rural populations and the need for affirmative action to overcome the serious disparities where they exist are not given due emphasis (pp. 5-14).

We can reasonably conclude that the premises and rationale of ERT have not received the attention they deserve in the discourse on the post-MDG global development agenda.

\section{Restating the ERT Rationale}

Let me recall briefly the rationale of ERT and re-state a few key points about incorporating ERT in the agenda for combating poverty and building a sustainable future. In doing so, I draw heavily on the UNESCO-INRULED report entitled Education and Training for Rural Transformation: Skills, Jobs, Food and Green Future to Combat Poverty (See UNESCO-INRULED, 2012).

The basic premise of this report is that poor rural people find it very difficult to manage the multiple risks they face arising from their personal and household circumstances, the natural and climatic hazards, and their economic and development situation at national and global levels. The rural poor, the majority of the poor in most developing countries, therefore, cannot seize the opportunities that may exist or arise for them in agriculture and the non-farm economy alike. Moreover, the overarching global and national challenges 
of fighting poverty and building the sustainable future cannot be met unless the problems facing the rural majority in the developing countries are effectively addressed.

In the least developed countries, 45 percent of the population and in developing countries as a whole one-third of the people will still be rural residents in 2050 .

These numbers add up to 2.6 billion people today and will surpass 3 billion by 2050 . The overarching global and national challenges of fighting poverty and building the sustainable future cannot be met unless the problems facing the rural majority in the developing countries are effectively addressed.

The term rural transformation - rather than rural development, rural change or rural education - was used advisedly to convey a vision of a pro-active and positive process of change and development of rural communities in the context of national and global changes. Education was seen as a key instrument for shaping and fulfilling the goal of rural transformation. A transformative view of rural change is not a denial of the general notion of rural development. It is merely an argument for giving up the linear and dichotomous view of development in favor of a heterogeneous, multidimensional and transformative view of national and rural development.

The focus on rural transformation called for recognizing new dimensions in the criteria for judging quality and relevance of educational activities. The rapidly changing rural scene and the dynamics of rural-urban interaction required flexibility and creativity in educational programs, not often found in the conventional formal system.

The concerns and priorities of rural people and the transforming rural communities needed to figure specifically and prominently in the educational responses to the contextual trends and influences that have a bearing on national education systems. For example, the human rights perspective, human development imperatives of education, effects of the new information technology, and the crucial importance of pursuing sustainable development objectives needed to be assessed from the point of view of advancing rural transformation.

\section{Skills, Jobs and Poverty}

The unemployment and underemployment of over a billion people is the greatest single direct obstacle to reducing absolute poverty - the overarching MDG goal. There is a massive mismatch between work to be done and people who need jobs. This gap has to be bridged by skills development and policies and actions to use the skills in decent jobs that are socially beneficial and personally rewarding.

Understanding the role of skills development in combating rural poverty requires a better grasp of the pathways out of poverty for rural people.

The solutions to the problems noted in fact did not lie only within the rural communities in the poor regions themselves or within the usually defined scope of the interventions in rural areas. Longer term and broader interventions within a larger regional framework 
were considered necessary. Coordinated infrastructure development, improvement of social services, investments focused on job creation, availability of credit under appropriate terms, safety nets to reduce vulnerability of households, and education, training and appropriate skill formation activities as well as support to orderly migration of workers to locations with better job prospects were seen as the appropriate interventions. All these needed to be carried out with a coordinated approach.

A sample of analytical evidence from Sub-Saharan Africa and Asia sheds light on the connection between education, skills and jobs, on the one hand and the economic and political policy directions for fighting rural poverty on the other. The obstacles that had to be overcome for success in fighting poverty were of several kinds:

i) Poor natural resource endowment - shortage of farmland, shortage of water and inhospitable climatic and ecological condition for improving agricultural productivity, both with smallholders or moving into larger commercial production.

ii) Infrastructure deficiency - poor roads, inadequate irrigation and water supply, insufficient energy and power, and insufficient investments for these purposes.

iii) Institutional deficiencies of several types - lack of credit in accessible terms for the poor, political and bureaucratic obstacles to labor mobility, absence of social safety net, such as health care and child and old age benefits, insurance against catastrophe, protection against natural disasters and other vulnerabilities, and poor civic governance in general.

iv) Socio-cultural obstacles - language and ethnicity as obstacle to labor mobility or accessing economic opportunities.

v) Human development deficiencies - poor quality of primary education that does not ensure basic literacy and numeracy skills for many children, particularly the poor; lack of secondary general education and appropriate skills development, and scarce tertiary education that could bring technical know-how and support technology adaptation in rural areas.

Not mentioned in this enumeration based on the country investigations are insufficient non-formal and informal skill development and insufficient general adult and lifelong learning opportunities. Also not specifically mentioned are commonly observed phenomena, such as, corruption that seriously undermine sound and promising projects; improper political patronage and interference; and clans, tribes and caste rivalries in many societies affecting development initiatives adversely.

\section{Jobs and Escaping Rural Poverty}

It is clear that many rural people will need to move from traditional agriculture-based occupations to non-farm activities and many will need to move in search of jobs to towns and cities. Many will need skills that are different from those of their parents and these needs keep changing at a faster pace than before. But how exactly are skills turned into 
gainful and rewarding jobs? And how and what kind of employment creation can lift people out of poverty in rural areas?

International Labour Organisation (ILO) proposed the adaptation and application for rural economic activities its Global Employment Agenda (GEA) and the related Decent Work Agenda (DWA) as the framework for shaping policies and actions to reduce poverty by generating more and better jobs. ILO advocates the integration of economic and social objectives, and a well-orchestrated combination of measures in the areas of employment promotion, rights at work, social protection and social dialogue. It argues that expanding "decent work" for rural people opened the avenue out of poverty. Decent work can be regarded as a productive factor; and social policies based on decent work have a dynamic role to play in promoting a healthy economy and a just society (ILO, 2003).

The insight underlying GEA and the decent work concept is that employment is the missing link between growth and poverty reduction. It also emphasizes that sustainable poverty reduction requires simultaneously social transfers, investments in social and physical infrastructure and good labor market performance. These constitute key policy orientations for any country to succeed in reducing poverty in rural areas (ILO, 2003; ILO, 2008).

To sum up, four general comments are pertinent about overcoming constraints to policies that promote land and labor productivity in rural areas.

First, the solutions to some of the major problems did not lie in specific interventions within the rural community or the locality, such as, those about social safety net and credit policy, and bureaucratic and legal barriers to labor mobility and labor market flexibility. The problems of farmland shortage and population pressure also required regional or even national strategies much beyond the boundaries of the rural localities.

Second, macroeconomic conditions and policies that were effective in promoting aggregate economic growth served as a positive backdrop for implementing poverty reduction actions; and the opposite in the case of slow growth.

Third, good quality primary and secondary general education was important for helping young people from poor households take advantage of better paying and higher productivity non-farm employment opportunities. This was necessary for participating in occupation-specific skill training or gaining entry-level spots in firms for on-the-job or in-house training. The corollary to this condition was that education and training were not particularly a requirement for low-productivity, low-wage and low-skill jobs in the informal sector, but are critical if the aim is to change this situation.

Finally, different kinds of constraints, education and training for skills development being a major one, point to the importance of finding ways of bridging various gaps between concepts and practices. These gaps are primarily between poverty reduction strategies and actions, on the one hand, and generation of skills and jobs, on the other. It is a 
problem of bringing the two areas of policy and strategy discussion, which have continued somewhat in parallel, into one universe of discourse. The links, sometimes rhetorically recognized, need to be clarified and sharpened. The implications for policy and coordinated action that addresses the interfaces of skills, employment and poverty reduction among rural people need to be spelled out and acted upon.

\section{Skills and Jobs for a Green Future}

Climate change affects the poor disproportionately and has far-reaching consequences for agricultural and rural development. As a major source of greenhouse gas (GHG) emissions, agriculture also has huge potential to reduce emissions through reduced deforestation and changes in land use and agricultural practices. Effects of climate change make poor people the first victims and the greatest sufferers of environmental degradation. The rural poor are more vulnerable than others when it comes to environmental hazards and environment-related conflicts of interest, and are least able to cope with them when they occur. They also tend to be most dependent on the natural environment and on the direct use of natural resources, and are therefore most severely affected by environmental degradation and lack of access to natural resources.

The discourse on sustainable development and ways of enhancing skills and capacities of people points to at least three key concerns. These merit attention in shaping an integrated approach in education, training and relevant supportive strategies. These three concerns are: a) Social marginalization and disparity and claiming a stake for all in economic and social development; b) Coping with the feminization of poverty; and c) Promoting sustainable production and consumption for all, not just the poor, in the context of poverty reduction(Ahmed 2010).

An investigation carried out by ILO and the European Centre for the Development of Vocational Training (Cedefop) in 21 less and more developed countries examined the level of awareness and national positions about climate change impact and priorities. National study teams in the 21 countries focused on general issues of the green economy, rather than the rural economy or the agriculture sector. A number of points, highlighted by these statements, merits attention (Cedefop 2010):

- The majority of the people living in the rural areas, dependent on agriculture for employment and livelihood, will bear the brunt of the negative consequences of climate change. Yet the recognition of the impact on agriculture and rural people are uneven at best, and barely noted, in some cases. There is a focus on carbon emissions as the problem, which is ultimately a major source of the problem and the solution. But this appears to have distracted attention from the real and immediate impact on the lives of hundreds of millions of people by the proximate effects of climate change manifested in pressure on land and water and weather volatility. 
- Both the numbers in the workforce and the place of the rural economy within the national economy in the developing countries, albeit it is changing, offer possibilities that remain unexplored for adaptation to climate change, mitigation of the consequences, and indeed the possibilities of preventing some of the negative effects.

- In many instances, even when the impacts and the need for action are recognized and policy and goals for transition to the green economy are stated, actual progress in implementation and the political will and social mobilization of support are insufficient. Capacities and relevant skills for the transition to the green economy at different levels, overall and particularly in the rural communities, are a major constraint in most countries.

Broader economic and social adjustments are required. Transition to a greener economy focusing on agriculture and rural areas has to be part of broader long-term structural change in the economy. Socially responsible restructuring measures have to be adopted which do not punish further the poor and the disadvantaged in rural and urban areas. The costs of adjustments and how these are shared recognizing prevailing inequalities and disparities have to be examined and public understanding and consensus have to be developed about policies. In other words, the priority for transition to a green economy is to combat climate change and environmental degradation and remove their negative effects.

In short, according to the study, among the developing countries, most have attempted to articulate environmental policies and many have grappled with policy priorities and strategies in skills development, but the two often have continued on parallel tracks without an intersection of the two. Overall, three broad policy-related difficulties confronting countries in their attempts to move to a low-carbon economy can be identified. These are: i) lack of enforcement of environmental regulations, sometimes with related legislation, already adopted; ii) cursory or little attention to skills implication of responses to climate change; and iii) insufficient attention to implications for the informal economy.

One effect of weak enforcement of environmental laws is to reduce the demand for the new skills needed to comply with them. Most of the documentation on adaptation and mitigation measures, policies, strategies, action plans and programs lack the skills response component. Mechanisms established for identifying, monitoring, anticipating and providing skills do not usually include representation from environment ministries. Similarly, ministries, agencies and institutions concerned with education and training are mostly not involved in developing environmental policies (ILO, 2011, pp. 53-54).

The large size of the informal economy in developing countries indicates that measures to restructure the economy and skills training mainly in the organized sectors will leave large proportions of the people, especially in rural areas, without access to skills development and new job opportunities. Reliable quantitative estimates are hard to come by, but it can be reasonably assumed that there is large overlap between informal sector work and rural employment. 
To sum up, the priority for transition to a green economy requires an integrated view of urban and rural areas, with special attention to agriculture and related economic activities, rural areas, and rural people, if only because they constitute the majority who are affected and they also can contribute to the solutions.

\section{Conclusion}

As noted above, the report of the Secretary General of the United Nations in July 2013 about the global development agenda beyond 2015 mentions that "rural prosperity, land management and secure ecosystem services should form an integral part of sustainable urbanization and economic transformation" (p. 15). The stress is on sustainable urbanization rather than sustainable integrated urban-rural development.

The recognition of the High Level Panel appointed by the Secretary General that "the most pressing issue is not urban versus rural, but how to foster a local, geographic approach to the post-2015 agenda" is critical from the point of view of ERT. However, this is not followed through in the argumentation and the positions taken in the HLP report. The bias in the panel in its position on the urbanization issues and sustainable development is in favor of solutions that are framed in terms of the cities' needs, rather than from the point of view of an integrated and mutually supportive regional perspective encompassing urban, peri-urban and rural, recognizing that the boundaries are transient and blurred.

The Sustainable Development Solutions Network emerging from the RIO+20 conference in 2012 is influential in defining the issues and setting the post-2015 development agenda. It has identified 13 themes on which thematic groups have been elaborating inputs to the post-2015 global agenda-setting process. The thematic groups on agriculture, cities and education, most relevant to ERT, have proposed targets and indicators. As discussed above, persistent disadvantages of rural populations and the need for affirmative action to overcome the serious disparities where they exist are not given due emphasis. For example, the concerns and priorities of rural people and the transforming rural communities need to be figured out specifically and prominently in the post-2015 education agenda. Similarly, the human rights perspective, human development imperatives of education, effects of the new information technology, and pursuing the sustainable development objectives need to be assessed from the point of view of promoting rural transformation.

The debate on the global development agenda will continue until the fall of 2015 when the global agenda for 2030 will be adopted at the United Nations. A skewed perspective on the urban-rural issue remains a serious concern which is liable to distort the new development direction and thus undermine progress towards combating poverty and building the green future. 


\section{Note}

${ }^{1}$ This paper is based on the keynote speech at the concluding session of the 4th ERT

Conference, Kasetsart University, Bangkok, September 18-20, 2013.

\section{References}

Ahmed, M. (2010). Economic dimensions of sustainable development: The fight against poverty and educational responses. International Review of Education, 56(2-3), 236253.

Ahmed, M. (2013a). Comments on HLP final report. Geneva: Network for International Policies and Cooperation in Education and Training.

Ahmed. M. (2013b). Squaring the circle: Relevance of post-2015 EFA and development agenda at the country level. NORRAG News 49, Education and Development in the Post-2015 Landscapes, 19-20.

CEFEDOP. (2010). Skills for green jobs: European synthesis report. Luxembourg:

Publications Office of the European Union.

High Level Panel. (2013, May 30). A new global partnership: Eradicate poverty and transform economies through sustainable development. Report of the High Level Panel to the Secretary General. New York, NY: United Nations.

ILO. ( 2003). Global employment agenda. Geneva, Switzerland: Author.

ILO. (2008). Promotion of rural employment for poverty reduction. Report presented at the International Labour Conference, 97th Session, Report IV, Geneva, Switzerland.

ILO. (2011). Skills for green jobs: A global view. Synthesis report based on 21 country studies. Geneva, Switzerland: Author.

SDSN (2013a). Sustainable agriculture and food systems: Technical report for the post2015 development agenda. New York, NY: Author.

SDSN. (2013b). Why the world needs an urban sustainable development goal. New York, NY: Author.

SDSN. (2013c). Early childhood development, education and transition to work: Report of thematic group 4. New York, NY: Author.

UNESCO-INRULED. (2012). Education and training for rural transformation: Skills, jobs, food and green future to combat poverty. Beijing, China: Author.

United Nations. (2013, July). A life of dignity for all: Accelerating progress towards the Millennium Development Goals and advancing the United Nations development agenda beyond 2015. Report of the Secretary-General to the 68th Session of the General Assembly. New York, NY: Author. 